\title{
Management of pediatric clival chordoma with extension to the craniocervical junction and occipito-cervical fusion: illustrative case
}

\author{
*Matthew A. Liu, MPH, ${ }^{1}$ Julian L. Gendreau, MD, ${ }^{2}$ Joshua J. Loya, MS, MD, ${ }^{1}$ Nolan J. Brown, BS, ${ }^{3}$ Amber Keith, BS, ${ }^{3}$ \\ Ronald Sahyouni, MD, MS, PhD, ${ }^{1}$ Mickey E. Abraham, MD, MS, ${ }^{1}$ David Gonda, MD, ${ }^{1,4}$ and Michael L. Levy, MD, PhD ${ }^{1}$ \\ ${ }^{1}$ Department of Neurosurgery, University of California, San Diego, La Jolla, California; ${ }^{2}$ Department of Biomedical Engineering, Johns Hopkins Whiting School of Engineering, \\ Baltimore, Maryland; ${ }^{3}$ Department of Neurosurgery, University of California Irvine, Orange, California; and ${ }^{4}$ Rady Children's Hospital San Diego, California
}

BACKGROUND Chordomas are rare malignant neoplasms that develop from the primitive notochord with $<5 \%$ of the tumors occurring in pediatric patients younger than the age of 20 . Of these pediatric chordomas, those affecting the craniocervical junction (C1-C2) are even more rare; therefore, parameters for surgical management of these pediatric tumors are not well characterized.

OBSERVATIONS In this case, a 3-year-old male was found to have a clival chordoma on imaging with extension to the craniocervical junction resulting in spinal cord compression. Endoscopic-assisted transoral transclival approach for clival tumor resection was performed first. As a second stage, the patient underwent a left-sided far lateral craniotomy and cervical laminectomy for resection of the skull base chordoma and instrumented fusion of the occiput to C3. He made excellent improvements in strength and dexterity during rehab and was discharged after 3 weeks.

LESSONS In pediatric patients with chordoma with extension to the craniocervical junction and spinal cord compression, decompression with additional occipito-cervical fusion appears to offer a good clinical outcome. Fusion performed as a separate surgery before or at the same time as the initial tumor resection surgery may lead to better outcomes.

https://thejns.org/doi/abs/10.3171/CASE21434

KEYWORDS chordoma; clival; craniocervical; occipito-cervical fusion; oncology; pediatric; skull base

Chordomas are rare malignant neoplasms that develop from the primitive notochord. These neoplasms mostly occur in adults between the ages of 30 and 70 whereas only $<5 \%$ of chordomas occur in patients younger than the age of $20 .^{1-3}$ Thus, chordomas in the pediatric population are even more rare and infrequent. When they do occur, they are found to mostly be located within the sacrococcygeal region $(\sim 50 \%)$, skull base $(25 \%-39 \%)$, and spinal column $(15 \%))^{2,4}$ In children specifically, they are most likely to occur intracranially and arise from the skull base, preferentially affecting the clivus, the spinal-occipital synchondrosis of the clivus, and the sella turcica. ${ }^{5}$

Initial symptoms of a chordoma often include progressive cranial nerve deficits that worsen over time. However, in children it often manifests with vague nonspecific complaints that can delay diagnosis of the disease until the tumor becomes large. ${ }^{6}$ This aspect of the disease makes achieving gross total resection difficult because the tumor is often diagnosed only after it is found to encroach on nearby critical neurovascular structures in addition to extending into the nearby craniocervical junction. ${ }^{7}$

The standard of care for this disease is initial gross total resection if feasible. This often requires a multistaged anterior and posterior approach that consists of endoscopic tumor debulking and a secondary open microscopic skull base approach tailored to the residual lesion., Achieving a gross total resection early in the disease process is paramount for optimizing long-term progression-free survival of the disease when coupled with stereotactic proton beam radiotherapy. ${ }^{1}$ Histopathology and immunochemistry can further assist in differentiating chordomas into conventional/myxoid, chondroid, and undifferentiated, which can be used to better stratify different progression-free survival outcomes. ${ }^{3,4}$

ABBREVIATIONS MRI = magnetic resonance imaging; OC = occipito-cervical; OCF = occipito-cervical fusion; SSEPS = somatosensory evoked potentials INCLUDE WHEN CITING Published November 22, 2021; DOI: 10.3171/CASE21434.

SUBMITTED July 27, 2021. ACCEPTED August 19, 2021.

* M.A.L. and J.L.G. contributed equally to this work.

(C) 2021 The authors, CC BY-NC-ND 4.0 (http://creativecommons.org/licenses/by-nc-nd/4.0/). 
In the pediatric population, gross total resection can be even more difficult to achieve because the tumor often extends to the craniocervical junction infiltrating the occipital condyles, atlas, and axis. This often necessitates removal of these structures during multiple stages of surgery. ${ }^{6,10}$ Removal of these structures, however, can potentially cause instability of the craniocervical junction. Thus, occipito-cervical fusion (OCF) can be performed to minimize morbidity of this resulting instability that may occur especially in the presence of spinal cord compression. Currently, evidence is limited to case reports of OCF after clival chordoma resection in the pediatric population, with no definitive guidelines provided. ${ }^{11}$ Therefore, the authors describe the case of a 3-year-old male patient with a clival chordoma with extension to the craniocervical junction who underwent resection using a multistaged surgical approach. He additionally underwent OCF with a good postoperative outcome.

\section{Illustrative Case}

\section{History and Examination}

A 3-year-old boy presented with weakness of the left upper (3/5 proximally; $2 / 5$ distally) and lower extremities (4/5) with no discernable cranial nerve deficits, dysmetria, or changes in reflexes. In addition, sensation to light touch was intact and the patient had a negative Hoffman and Babinski with no clonus at the ankle. Subsequent imaging demonstrated a clival mass causing mass effect upon the medulla and high cervical spinal cord with severe chronic spinal cord compression associated with mild edema within the spinal cord. The tumor extended to the craniocervical junction involving the anterior arch of $\mathrm{C} 1$ and the odontoid (Fig. 1). This resulted in chronic high cervical spinal cord compression. A chordoma was suspected, and a treatment plan was devised to provide spinal cord decompression, optimal resection of the lesion, and stabilization of the occipital-cervical junction.

\section{Operation}

As a first stage, an endoscopic-assisted transoral transclival approach for clival tumor resection was performed to debulk a major portion of the compressive portion of the lesion at the craniocervical junction. This included resection of the inferior third of the tumor-invaded clivus as well as the entirety of the odontoid process. Given that this approach did not provide ideal access to the anterolateral tumor burden at the skull base and high cervical canal, a second stage surgery was planned the following day while the patient remained intubated and sedated (Fig. 2A and B). As a second stage, the patient underwent a left-sided far lateral craniotomy and cervical laminectomy for resection of the ventrolateral tumor at the skull base and anterolateral to the spinal cord. Given the destabilization of the craniocervical junction resulting from the anterior resection, an instrumented fusion was performed from the occiput to C3 for stabilization (Fig. 3). This was performed in parallel with the far lateral craniotomy immediately after the resection portion of the surgery (Figs. 2C, 2D, and 3). Intraoperative neuromonitoring showed absent bilateral upper and lower extremity motor evoked potentials (MEPs) at baseline that did not change with either surgical procedure. Somatosensory evoked potentials (SSEPs) did improve after the first surgery with a return of right upper extremity SSEPs, after initially being absent, that was stable after the second operation.

After surgery, the patient exhibited transient postoperative quadriplegia. He also developed respiratory failure requiring mechanical ventilation, tracheostomy, and placement of a gastrostomy tube. However, he began to make excellent improvements in rehabilitation with good recovery of strength and dexterity and was discharged after 3 weeks. At his 4-week follow-up, his motor weakness and respiratory failure were completely resolved with full strength throughout (ASIA E), which was improved from his initial presentation (ASIA B). His 12-week follow-up was also unremarkable.

The etiology of his transient quadriplegia is somewhat unclear, as is the timing of his loss of function relative to the first or second surgery since he was intubated and sedated between the two interventions, which were 1 day apart. It was hypothesized to be a result of either the decompression itself and sudden re-expansion of the spinal cord after chronic compression or from a traumatic injury of the spinal cord with movement from instability prior to OCF.

Postoperative imaging showed a small amount of residual tumor within the anterolateral skull base adjacent to the medulla at the clivus near the superolateral resection cavity. The proximity of the lesion to the brainstem prohibited full-dose radiation therapy. As a result, approximately 3 months after the patient's initial surgery, a left-sided far-lateral craniotomy for reresection of the residual mass and debulking was performed to achieve separation prior to starting proton therapy. This surgery was performed without complication (Fig. 2E).

\section{Discussion}

\section{Observations}

Chordomas are inherently lytic and intimately involved with osseous structures necessitating extensive bone removal to achieve
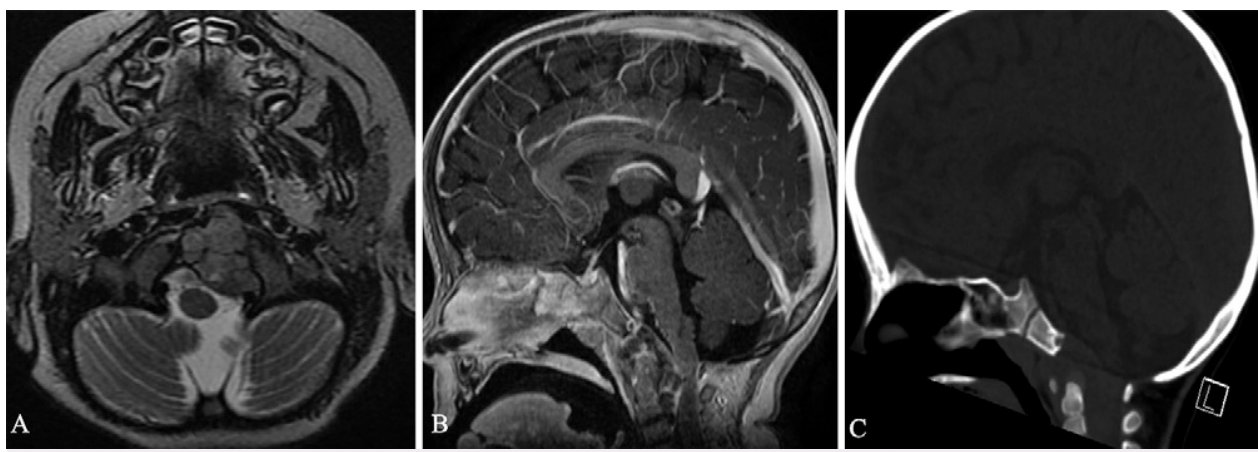

FIG. 1. Initial imaging of the patient's lesion. Clival lesions extend to the brainstem causing slight mass effect with associated cord compression and surrounding edema. The lesion extends into the craniocervical junction Images of T2 axial MRI (A); T1 sagittal MRI (B); computed tomography (CT) sagittal with bone window (C). 

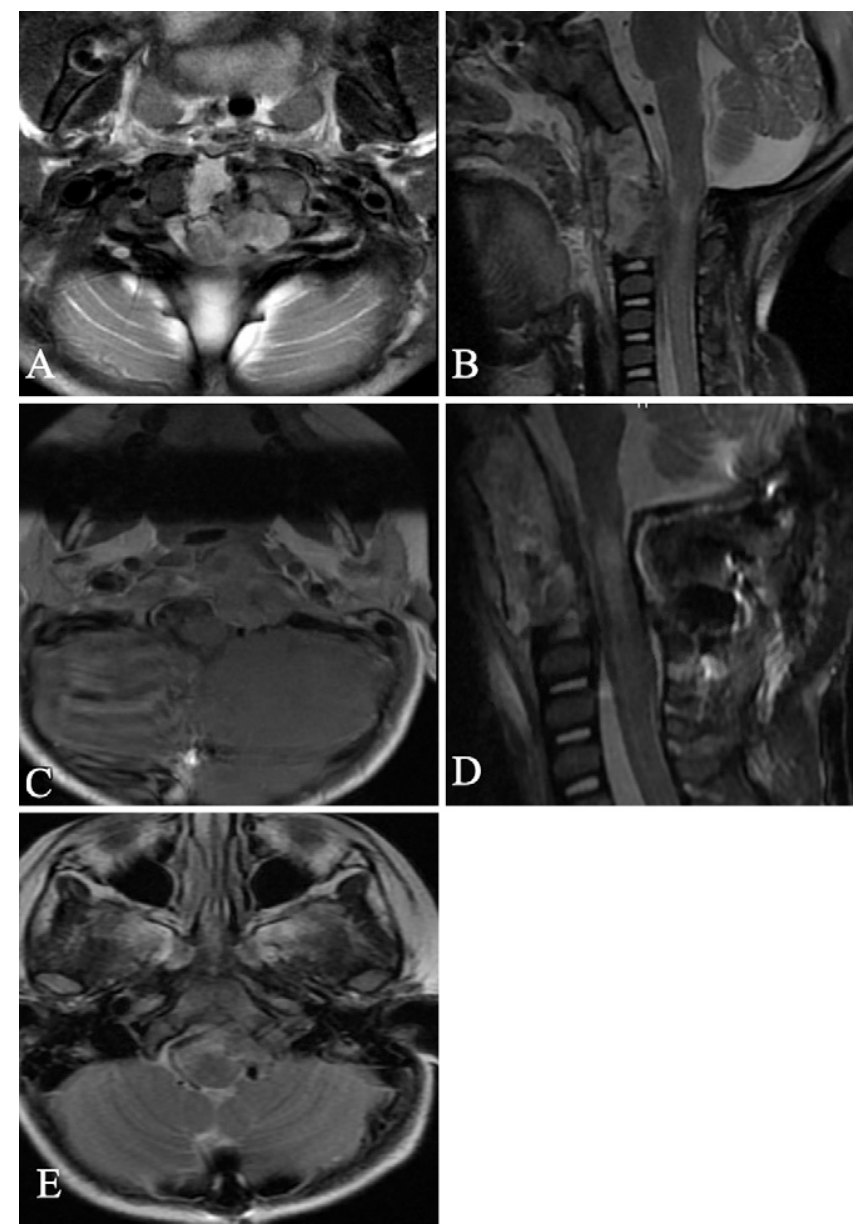

FIG. 2. Imaging after debulking and occipito-cervical fusion surgery. Axial (A) and sagittal imaging (B) T2 weighted MRI imaging after endoscopic transoral transclival resection of the chordoma. Resection cavity noted within the medial aspect of the tumor. Axial T1 (C) and sagittal (D) T2 weighted MRI imaging of the chordoma after far lateral craniotomy for tumor resection and occipito-cervical fusion. Decompression of the spinal cord is achieved. Axial (E) T2 MRI imaging after far-lateral craniotomy for debulking surgery of residual tumor.

aggressive resection, which can affect the stability of the occipitocervical junction when this region is involved by tumor. Given this aspect, surgical stabilization is an important consideration in planning surgical treatment of clival chordomas that extend into the atlantoaxial spine.

The stability of the articulation between the occiput and $\mathrm{C} 1$ relies on the odontoid as well as the cup-shaped configuration and the fibrous capsule of the occipito-atlantal joint. The anterior atlanto-occipital membrane, the posterior atlanto-occipital membrane, the tectorial membrane, the alar ligaments, the cruciform ligaments and the apical ligaments all contribute to the stability of the occipito-atlantal joint. ${ }^{12}$ Consequently, any surgical approach that alters or affects these stabilizers or their insertions can introduce instability. Preoperative destruction of the occipital condyle by invasive disease or extensive operative condylectomy during resection can also contribute to instability. ${ }^{2}$

As a result, in any procedure requiring extensive resection of pathology involving the craniocervical junction, the overarching questions are:

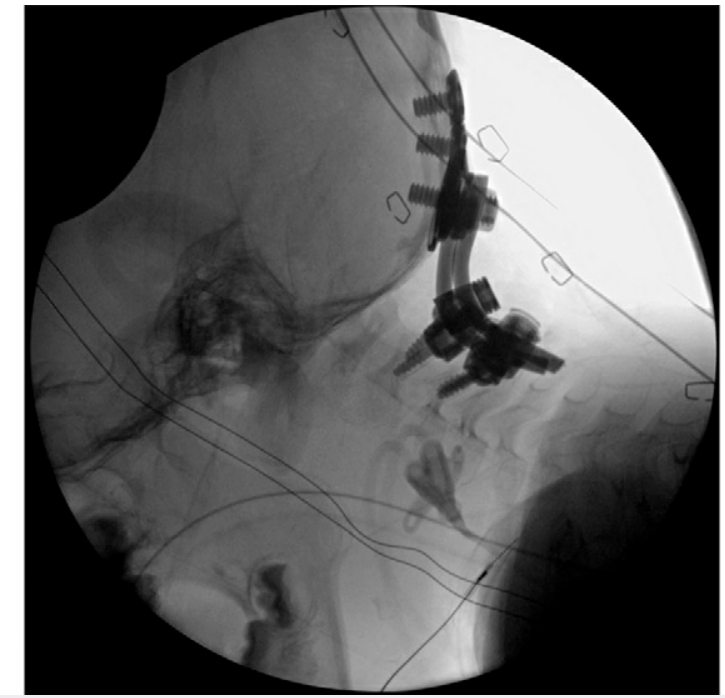

FIG. 3. Intraoperative lateral view fluoroscopy confirmed proper placement of the occipital cervical fusion.

what approaches should be taken to achieve the goals of surgical resection and what is the appropriate timing of surgical stabilization such as OCF? Although the indications for internal fixation in children are similar to those for adults, the data concerning techniques, complications, and outcomes of spinal instrumentation are mainly derived from either congenital anomalies or pediatric trauma cases in previous retrospective series. ${ }^{12-15}$ Decision making around OCF in the context of tumor surgery, such as in chordoma of the skull base, is not well established in children at this time.

Therefore, the authors examined all published literature to date on skull base chordomas that extend to the craniocervical junction in the pediatric population. The authors also assessed the clinical outcome and timing of OCF in these cases. Only a few case reports were found describing outcomes both with OCF (Table 1) $)^{9,16,17}$ and without OCF (Table 2). ${ }^{5,18}$

Overall, pediatric cases of OCF appear largely tolerated as evidenced by previous case reports of patients undergoing OCF in addition to chordoma resection. In terms of timing, OCF can be conducted before or after tumor resection. ${ }^{2}$ Advantages of performing OCF before, or at the same time as tumor resection include limiting potential postoperative morbidity or spinal cord injury that may result from instability resulting from resection of the chordoma and involved osseous structures. ${ }^{19}$ One retrospective study of adult patients found that OCF after clival chordoma resection was associated with complications such as wound dehiscence, encephalitis, and cardiac arrest, which has been associated with mortality. When an OCF was performed as a first stage with tumor resection to follow, there were no reported significant complications. When OCF occurs during the initial surgery, there appears to be less destabilization of the cervical spine, which decreases the likelihood of spinal cord trauma. ${ }^{2,20,21}$

Disadvantages of performing OCF before or at the same time as the tumor resection include the placement of metallic material such as rods, screws and cages which pose additional challenges to particle therapy both at the time of simulation and at the time of treatment. It limits radiotherapy by multiple beam-angle restrictions and 
TABLE 1. Review of pediatric studies of clival chordoma with OCF

\begin{tabular}{|c|c|c|c|c|c|c|c|}
\hline $\begin{array}{l}\text { Authors \& } \\
\quad \text { Year }\end{array}$ & Age, Sex & $\begin{array}{l}\text { Preoperative } \\
\text { Symptoms }\end{array}$ & Approach & Timing of Fusion & $\begin{array}{l}\text { Fusion } \\
\text { Levels }\end{array}$ & $\begin{array}{l}\text { Reason for } \\
\text { Fusion }\end{array}$ & Outcome \\
\hline $\begin{array}{l}\text { Joyce et al., } \\
2020^{16}\end{array}$ & $15, F$ & $\begin{array}{c}\text { Nasal obstruction, } \\
\text { dysphagia, } 8-10 \\
\text { pounds weight loss, } \\
\text { left tongue deviation }\end{array}$ & $\begin{array}{l}\text { Left extreme lateral } \\
\text { transodontoid approach }\end{array}$ & $\begin{array}{c}\text { In a second } \\
\text { operation after initial } \\
\text { resection }\end{array}$ & $\begin{array}{c}\text { OCF, } \\
\text { unspecified }\end{array}$ & $\begin{array}{l}\text { Transodontoid } \\
\text { approach }\end{array}$ & $\begin{array}{c}\text { At } 2 \text { months, } \\
\text { improvement of } \\
\text { cranial neuropathies, } \\
\text { tolerate oral intake }\end{array}$ \\
\hline $\begin{array}{l}\text { Eco et al., } \\
2019^{17}\end{array}$ & $5, M$ & Right shoulder pain & Far lateral approach & $\begin{array}{l}\text { During the initial } \\
\text { resection surgery }\end{array}$ & $\mathrm{O}-\mathrm{C} 2$ & $\begin{array}{l}\text { Arch of } \mathrm{C} 1 \\
\text { resection }\end{array}$ & $\begin{array}{c}\text { Neurologically intact } \\
\text { at } 42 \text { months with } \\
\text { stable oncological } \\
\text { status }\end{array}$ \\
\hline $\begin{array}{l}\text { Neil et al., } \\
2016^{9}\end{array}$ & $8, F$ & $\begin{array}{c}1 \text { week of } \\
\text { progressive upper } \\
\text { extremity weakness, } \\
1 \text { year history of } \\
\text { neck pain }\end{array}$ & $\begin{array}{l}\text { Multistaged: endonasal, } \\
\text { endoscopic and } \\
\text { microscopic transclival } \\
\text { approach, left and right } \\
\text { far-lateral approaches } \\
\text { with occipital cervical } \\
\text { fusion }\end{array}$ & $\begin{array}{l}\text { During left far lateral } \\
\text { approach (second } \\
\text { surgery) }\end{array}$ & O-C4 & Unspecified & $\begin{array}{l}\text { Good clinical } \\
\text { outcome }\end{array}$ \\
\hline
\end{tabular}

OCF = occipito-cervical fusion.

TABLE 2. Review of pediatric studies of clival chordomas extending to the atlantoaxial spine without OCF

\begin{tabular}{lllcc}
\hline Authors \& Year & $\mathrm{n}$ & Age Range & Approach & Outcome \\
\hline $\begin{array}{c}\text { Habrand et al., } \\
2016^{5}\end{array}$ & 1 & 9 years old & $\begin{array}{c}\text { Two subsequent and successful } \\
\text { approaches, otherwise unspecified }\end{array}$ & No postoperative morbidity \\
\hline $\begin{array}{c}\text { Tsitouras et al., } \\
2016^{18}\end{array}$ & 1 & 10 years old & TSO-TSP & Died of disease 38 months after surgery \\
\hline
\end{tabular}

TSO = transoral; $\mathrm{TSP}=$ transpalatal; $\mathrm{TSM}=$ transmandibular.

altering particle pathways. ${ }^{5}$ In addition, early OCF can make it more difficult to achieve gross total resection due to limitation in head positioning and narrowing of potential surgical pathways. There is a further concern in patients with early onset chordomas, which are often associated with craniovertebral abnormalities. Consequently, it may be better to wait for when the bones have had a chance to elongate and mature before performing any permanent stabilization. Instrumentation is also found to be associated with inhibiting growth of the cervical spine in up to one-third of patients receiving cervical fusion in patients $<16$ years old. ${ }^{22}$ To counter these disadvantages, an alternative option would include managing patients semiconservatively with external fixation and support. ${ }^{23,24}$ In these instances, second step surgery after the initial chordoma resection can be planned if conservative management fails, and the patients remain symptomatic or at risk; however, these devices also carry their own set of practical challenges and morbidities.

\section{Lessons}

In pediatric patients with clival chordomas involving the craniocervical junction with concern for postoperative instability, OCF before or at the same time as the initial tumor resection surgery appears to allow for minimal postoperative morbidity. In most cases, performing an OCF first did not interfere with achieving maximal safe resection; however, this decision must be made on a case-by- case basis. In cases in which OCF is not immediately feasible due to concerns of the inability to achieve gross total resection or concerns of inhibiting radiotherapy, an alternative option includes managing patients semiconservatively with external fixation and secondary surgery later in time.

\section{References}

1. Erazo IS, Galvis CF, Aguirre LE, Iglesias R, Abarca LC. Clival chondroid chordoma: a case report and review of the literature. Cureus. 2018;10(9):e3381.

2. Park HH, Park JY, Chin DK, Lee KS, Hong CK. The timing of fusion surgery for clival chordoma with occipito-cervical joint instability: before or after tumor resection? Neurosurg Rev. 2020;43(1): 119-129.

3. Ridenour RV 3rd, Ahrens WA, Folpe AL, Miller DV. Clinical and histopathologic features of chordomas in children and young adults. Pediatr Dev Pathol. 2010;13(1):9-17.

4. Hoch BL, Nielsen GP, Liebsch NJ, Rosenberg AE. Base of skull chordomas in children and adolescents: a clinicopathologic study of 73 cases. Am J Surg Pathol. 2006;30(7):811-818.

5. Habrand JL, Datchary J, Bolle S, et al. Chordoma in children: casereport and review of literature. Rep Pract Oncol Radiother. 2016; 21(1):1-7.

6. Rassi MS, Hulou MM, Almefty K, et al. Pediatric clival chordoma: a curable disease that conforms to Collins' law. Neurosurgery. 2018;82(5):652-660. 
7. al-Mefty O, Borba LA. Skull base chordomas: a management challenge. J Neurosurg. 1997;86(2):182-189.

8. McDowell MM, Zwagerman NT, Wang EW, Snyderman CH, TylerKabara EC, Gardner PA. Long-term outcomes in the treatment of pediatric skull base chordomas in the endoscopic endonasal era. J Neurosurg Pediatr. 2021;27(2):170-179.

9. Neil JA, Garber ST, Dailey AT, Couldwell WT. Management of complex pediatric chordoma: transnasal and bilateral far-lateral approach for resection with 0-C4 fusion: 3-dimensional operative video. Oper Neurosurg (Hagerstown). 2016;12(4):392.

10. Ahmed R, Traynelis VC, Menezes AH. Fusions at the craniovertebral junction. Childs Nerv Syst. 2008;24(10):1209-1224.

11. Menezes $\mathrm{AH}$. Craniovertebral junction neoplasms in the pediatric population. Childs Nerv Syst. 2008;24(10):1173-1186.

12. Bejjani GK, Sekhar LN, Riedel CJ. Occipitocervical fusion following the extreme lateral transcondylar approach. Surg Neurol. 2000; 54(2):109-116.

13. Grover PJ, Harris LS, Thompson DNP. Craniovertebral junction fixation in children less than 5 years. Eur Spine J. 2020;29(5):961-969.

14. Martinez-Del-Campo E, Turner JD, Rangel-Castilla L, SorianoBaron H, Kalb S, Theodore N. Pediatric occipitocervical fixation: radiographic criteria, surgical technique, and clinical outcomes based on experience of a single surgeon. $J$ Neurosurg Pediatr. 2016;18(4):452-462.

15. Hassler KR, Jamshidi R, Vail SJ, et al. Atlanto-occipital transarticular screw fixation for the treatment of traumatic occipitocervical instability in the pediatric population. World Neurosurg. 2020;140: e81-e86.

16. Joyce EJ, Cohen MA, Ho W, Brockmeyer DL, Couldwell WT. Extreme lateral transodontoid approach for resection of clival chordoma: 2-dimensional operative video. Oper Neurosurg (Hagerstown). 2020;19(3):E298.

17. Eco LC, Brayton A, Whitehead WE, Jea A. Reconstruction of the anterior craniocervical junction using an expandable cage after resection of a $\mathrm{C} 1$ chordoma in a 5-year-old child: case report. J Neurosurg Pediatr. 2019;24(1):62-65.

18. Tsitouras V, Wang S, Dirks $P$, et al. Management and outcome of chordomas in the pediatric population: The Hospital for Sick Children experience and review of the literature. $J$ Clin Neurosci. 2016;34:169-176.

19. Shin H, Barrenechea IJ, Lesser J, Sen C, Perin NI. Occipitocervical fusion after resection of craniovertebral junction tumors. J Neurosurg Spine. 2006;4(2):137-144.
20. Dhall G, Traverso M, Finlay JL, Shane L, Gonzalez-Gomez I Jubran $R$. The role of chemotherapy in pediatric clival chordomas. J Neurooncol. 2011;103(3):657-662.

21. Rastatter JC, Walz PC, Alden TD. Pediatric skull base reconstruction: case report of a tunneled temporoparietal fascia flap. J Neurosurg Pediatr. 2016;17(3):371-377.

22. Goldstein HE, Neira JA, Banu M, et al. Growth and alignment of the pediatric subaxial cervical spine following rigid instrumentation and fusion: a multicenter study of the Pediatric Craniocervical Society. J Neurosurg Pediatr. 2018;22(1):81-88.

23. Hong J, Zaman R, Coy S, et al. A cohort study of the natural history of odontoid pseudoarthrosis managed nonoperatively in elderly patients. World Neurosurg. 2018;114:e1007-e1015.

24. Tomaszewski R, Sesia SB, Studer D, Rutz E, Mayr JM. Conservative treatment and outcome of upper cervical spine fractures in young children: a STROBE-compliant case series. Medicine (Baltimore). 2021;100(13):e25334.

\section{Disclosures}

The authors report no conflict of interest concerning the materials or methods used in this study or the findings specified in this paper.

\section{Author Contributions}

Conception and design: Loya, Liu, Gonda, Levy. Acquisition of data: Gendreau, Brown, Keith, Gonda. Analysis and interpretation of data: Loya, Liu, Gendreau, Brown. Drafting the article: Loya, Liu, Gendreau, Brown, Abraham. Critically revising the article: Loya, Liu, Gendreau, Brown, Sahyouni, Abraham, Gonda. Reviewed submitted version of manuscript: Loya, Liu, Gendreau, Brown, Sahyouni, Levy. Approved the final version of the manuscript on behalf of all authors: Loya. Administrative/technical/material support: Loya, Liu, Levy. Study supervision: Loya, Gonda, Levy.

\section{Correspondence}

Joshua J. Loya: University of California, San Diego Medical Center, La Jolla, CA. jjloya@health.ucsd.edu. 